\title{
The application of green architecture idea in design
}

\author{
Qin Liping \\ Civil Construction Engineering Department, Hubei Polytechnic University, Huangshi, China \\ qinlp_hbpu@163.com
}

\begin{abstract}
Keywords: green building, architectural design, energy saving, living environment
Abstract. with the promotion of the concept of sustainable development, green building design is more and more widely used in architectural design. This article has carried on the research to the green building design present situation, has analyzed the green building design idea content and the principle, and has carried on the elaboration to the green building design in the architectural design application.
\end{abstract}

\section{Introduction}

With the gradual opening of our society and the rapid development of economy, people's demands for architecture are becoming higher and higher, and more and more functions and functions of buildings can be expected. The construction of the building needs a lot of manpower, material resources and resources. At the same time, the construction of the building will inevitably bring about some environmental problems. In order to further enhance the architectural function and practical performance, and meet the new expectations of architecture, architects need to consider more needs in the design of buildings. While meeting people's needs, we should reduce the impact on the environment, and achieve harmonious coexistence between man and nature, and harmonious coexistence. With the development of economy, our country's resources and energy are in short supply day by day, and the waste of energy has become an increasingly prominent problem. As a human being on earth, everyone has the duty to make contributions to his homeland, reduce pollution, and maintain the long-term development of his homeland. It is also to provide a better living environment for oneself. As a result, architects need more attention to the relationship between nature and architecture.

\section{Construction Development at the Present Stage}

Abroad, as early as mid twentieth Century, Victor Ogiya gave a detailed summary of a series of architectural designs for architects to make effective use of natural resources, at the same time, A professor at the Technical University of Berlin in the Federal Republic of Germany has proposed the concept of bioclimatic architecture. Since 70s, Thomas Herzog applies the concept of green to architectural design, India architect Corea explored and studied the "low technology" green design. In the early $80 \mathrm{~s}$, in our country, extensive exploration of the greening of the building was carried out, and a lot of theories in theory are put forward, achieved efficient combination of theory and Practice.

\section{Green Building Concept and Design Content}

\section{the Concept of Green Building}

From a macro point of view, what we call green building is divided into three kinds according to the overall evaluation value. 1. when the overall value is negative, the building is a green building system based on negative input. 2. when the total value is zero, the green building system is in equilibrium. 3. the total value is positive when the existing environment is based on the green building system. As a matter of fact, there are only third buildings that can really be built. In general, according to the building meets the following point of view, whether the building can be become the green building: building the inherent pattern to reconsider the transformation of the old, make 
use of the original environment, new building materials, the unnecessary consumption of resources is reduced to the minimum, the final realization of resource recycling.

\section{Green Building Design Content}

First, we shall consider the full time of building construction to demolition. It takes a very long time to start building, building, putting into use, and many of the following. We need to build from the building, we have to consider the overall duration of the building construction projects as a whole. In the construction process may encounter problems ahead of schedule, in order to avoid unexpected accidents during construction, extend the time limit. Enhance the efficiency, green and sustainability of the building on the basis of quality assurance. This design from the perspective of green environmental protection, the initial construction will cost more money, relatively high construction costs. But in the late use of the construction process, the environmental benefits and green nature of the building can be gradually reflected, and gradually make the funds back.

Second, green buildings can save resources to a great extent. The conservation of various resources and energy is one of the important contents of green architecture. By incorporating green features into the design, you can save water, electricity, gas, and other resources. Also through the construction performance to achieve green environmental protection, reduce construction pollution. In the process of building design, in order to make the green development more obvious and more integrated into life, designers need to spend more time on the environmental performance of the building. The use of clean energy: solar roof, water source heat pump heating and cooling; use of new construction methods such as prefabricated construction, effectively avoid the air pollution caused by the construction of the building in the construction process. The consumption of energy is also greatly reduced, and in the latter part of the process, the concept and development of green energy utilization are maintained.

Third, the function of the building performance also has higher requirements. In line with the principle of environmental protection and energy conservation, green building green purpose is to achieve long-term sustainable development, the use of building materials can not harm the user's health, or environmental damage caused by environmental pollution problems. Therefore, while paying attention to the maximization of the green performance of the building, considering the beauty, practicability and comfort of the exterior, the building can be realized in many ways.

Finally, in order to achieve harmony between man and nature, architectural design takes into account the harmonious relationship between man and nature as much as possible. Green building naturally aims at environmental protection, and its design revolves around environmental protection. When the basic framework of architectural design, not only considering the building function, but also consider the situation in today's social resources, reduce the consumption of energy and resources, reduce the construction cost, so that the design and development of building a sustainable, do people and natural and good development.

\section{Green Building Design Principles}

The design of a building is first designed to provide a better environment for consumers. Therefore, in the architectural design, we should grasp the relationship between the good people for the construction and the natural environment, and try to find the unity and balance between the two of the two. Ensure harmony with nature and harmony. Let the green elements more and green design concept in the construction of withdrawals, management and application of design science, improve building comfort, efficiency and environmental protection, provide a more comfortable living environment for people. Give priority to the orientation of the building, and let the sunshine bring warm experience for the users every day. Second, the need to set up a building to protect the environment for the principle, not at the expense of the environment as the cost to build the stairs. 
The construction process will have a greater impact on the surrounding natural environment, the air will contain a lot of dust, respirable particles and harmful substances in the naked eye cannot see, the water may also impact, if not properly controlled, may cause water pollution, water for residents to bring inconvenience. Therefore, in the construction of construction before the construction, to the construction of the existing residents or other buildings to investigate, to ensure that the impact of construction as small as possible. The energy consumption of the construction industry is relatively large, and the consumption of the required energy should be rationally planned and operated in order to ensure the efficient use of energy. Enhance the efficiency of energy utilization, that is, indirectly enhance the green performance of buildings. When designing a building, minimize pollution and optimize the overall overall performance of the building. In order to reduce environmental pollution, in the construction process, all construction activities need to take science as the principle and maximize the green performance of the building.

\section{Analysis of the Actual Application of Green Building}

\section{Structure System}

In modern architectural design, it must be combined with the actual situation, such as the shape of the building, the seismic capacity and complexity, to ensure the overall structure of the seismic capacity, and then use elastic, elastic-plastic analysis. For different positions, different reinforcement schemes are used, so that the effect of seismic action on the structure can be reduced.

\section{Spatial Organization}

The development level of a city can be reflected in a large extent by the architecture of the city, and the construction level is also a symbol of the development of the city. When designing a building, designers should concentrate on the overall function of the building and co-ordinate the planning. Both to design a beautiful appearance of the building, but also to ensure that the construction of practical and convenient, reasonable. Aesthetics is one aspect of architecture, and more important, of course, is the function of architecture. New modern architecture, designers should minimize the use of glass curtain wall as the exterior of the building, the architectural design should always be adhering to the concept of green development. The appearance of the building conforms to the development of the green building, and the reduction of the glass surface illumination can reduce the light pollution.

\section{Building Energy Efficiency}

When considering the function of building energy saving, the designer should take into consideration the adjustment function of the building. Winter cold environment, the role of building insulation fully considered; hot summer climate, taking into account the construction of ventilation and cool effect, to keep the indoor air fresh. In this way, the air-conditioning can be reduced to some extent, and the energy consumption can be reduced. From the side to achieve energy-saving effect.

\section{Conclusion}

With the development of economic level, the damage to the environment is more and more serious, and the living environment changes accordingly. The building should be built as far as possible to maintain green development, in the design, adhering to the concept of green design, so that construction and ecology coexist harmoniously. Green buildings can also improve people's living standards and quality of life. In order to make the green building information obtained more publicity, in addition to considering the development of green building designers, to expect to 
achieve the final results of building and environment to achieve a better balance, to achieve green development, harmonious development.

\section{Acknowledgments}

The present research is supported by 2014' Youth Foundation Project of Hubei Natural Science Foundation (2014CFC1088).

\section{Reference}

[1] Tong Wei. The embodiment of green architectural design concept in industrial architectural design. Building Materials Technology and Application. 2012, (3): 29-31. (in Chinese)

[2] Yu Chunpu. On thinking of how to promote green building design. Journal of Architecture. 2013, (10): 50-52. (in Chinese)

[3] Zhang Zhiyong, Jiang Yong. Research on green building design tools. Journal of Architecture. 2015, (3): 78-80. (in Chinese)

[4] Wu Xiangyang. Two methods of green building design. Journal of Architecture. 2014, (9): 11-14. (in Chinese)

[5] Liu Fuying, Li Tianshu, Zhao Jun. Principles and objectives of green building design. Building Technology. 2013, (3): 212-215. (in Chinese)

[6] Cheng Xiaoqiong. Relationship between green building design and green energy saving building. Sichuan Building Materials. 2012, (4): 99-103. (in Chinese)

[7] Xu Jihang, Liu Xiao, Xiao Dawei. Green building design is suitable for the combination of art and technology innovation. South Building. 2013, (1): 57-59. (in Chinese)

[8] Jiang Changzheng, Zhou Qinghua. How to embody the principles of green building design under realistic conditions. Anhui Architecture. 2012, (1): 13-14. (in Chinese) 